\title{
What can we learn from atomistic simulations of bioactive glasses?
}

\author{
Alfonso Pedone and Maria Cristina Menziani \\ Dipartimento di Scienze Chimiche e Geologiche, Università degli Studi di \\ Modena e Reggio Emilia, Via G. Campi 183, 41125 Modena (Italy)
}

\section{Corresponding author:}

\author{
Alfonso Pedone \\ Dipartimento di Scienze Chimiche e Geologiche, Università degli Studi di Modena \\ e Reggio Emilia, Via G. Campi 183, 41125 Modena (Italy) \\ alfonso.pedone@unimore.it
}

\begin{abstract}
In the last decades, most experimental efforts have been devoted to design bioactive glasses with enhanced biological and mechanical properties by adding specific ions to known bioactive compositions. Concurrently, computational research has been focused to the understanding of the relationships between bioactivity and composition by rationalization of the role of the doping ions. Thus, a deep knowledge of the structural organization of the constituent atoms of the bioactive glasses has been gained by the employement of ab initio and classical molecular dynamics simulations techniques. This chapter reviews the recent successes in this field by presenting, in a concise way, the structure-properties relationships of silicate, phospho-silicate and phosphate glasses with potential bioactive properties.
\end{abstract}




\section{Introduction}

Bioactive glasses are widely employed for repair and replacement of diseased and damaged bone tissues, as bioactive coatings for bioinert metal/alloy implants, as toothpaste additives, and for several other biomedical applications[1,2].

Once in contact with body fluids, a rapid sequence of chemical reactions occurs at the surface of the bioactive glasses yielding to the formation of a hydroxycarbonate apatite (HCA) layer similar to bone mineral. HCA interacts with collagen fibrils to integrate with the host bone, giving rise to a strong chemical interface[3].

Since bioactivity strongly depends on the release of ionic species in the physiological environment, a prerequisite for straightforward prediction of the bioactive response of glasses is the correct understanding, at atomic level, of the structural organization of the constituting components, and of their modifications occurring over (sub)-nanometer scales, when the glass composition is altered. With this knowledge, new glass compositions for biomaterials with more attention to the application needs of the end users can be rationally designed reducing development costs, and speeding up the time to market.

Understanding the structure of glass is crucial but not trivial. The combination of advanced characterization techniques is required to collect different, complementary information of amorphous structures[4]. The data obtained often depict apparent contradictory structural evidences, and are of difficult interpretation.

Thus, in the last years a fervent computational research activity has been carried out with the aim of supporting in the interpretation of the experimental results. In particular, atomistic computer simulations have shown to provide a detailed picture of the glass structures, and precious information on the structure-properties relationships of complex glasses[5-9]. In fact, the structural and dynamical features that control dissolution and bioactivity cover length and time scales accessible to molecular dynamics (MD) simulations[10-14] Therefore, computational studies have now remarkably advanced the understanding of bioactive glasses, as documented by the numerous reviews and perspective articles published in recent years $[9,10,12,13]$

This chapter reviews the recent efforts to uncover sound relationships among the structure of crucial components and the physico-chemical properties of silicate, phospho-silicate and phosphate glasses with potential bioactive properties.

The chapter is organized as follows: first computational details for classical and ab-initio MD simulations are given with emphasis on critical points for oxide glasses treatment, then some important structural descriptors derived from the computational simulations are described. Section 4 summarizes the key structural features of silicate glasses, and the determinants of glass bioactivity are discussed. Some important computational results that allow significant insight into the effect of dopants such as $\mathrm{Mg}, \mathrm{Sr}, \mathrm{Zn}, \mathrm{Ga}, \mathrm{Al}, \mathrm{Ce}, \ldots$ on glass structure are then reviewed and compared with the available experimental data. The salient features of the glass 
surface are summarized in section 5. Finally, the computational description of Phosphate glasses is reported.

\section{How to obtain the Glass Structure models. A brief overview of Classical and $a b$-initio Molecular Dynamics}

\subsection{Classical Molecular Dynamics.}

The melt-and-quench approach commonly used to obtain glasses through MD simulations mimics the experimental process. In this approach, the glass structure is represented by a classical ensemble of particles in a box, interacting through empirical force fields.[14]

The Newton's equations of motion for each particle in the ensemble is solved with an iterative process: positions and velocities are updated in small increments of time, known as timesteps. Once equilibration is reached, the structure of the glass is obtained as an average over a large number (thousands or hundred-thousands). Large system sizes, on the order of $\sim 10^{4}$ atoms, is now accessible with a high level of accuracy, thanks to the accurate force fields now available.[15-18] Moreover, models of length size between 2 and $10 \mathrm{~nm}$ yield relevant structural properties for the glass dissolution with high statistical accuracy.

The interatomic pair potential based on the Born model can be written as:

$$
U_{i j}(r)=\frac{q_{i} q_{j} e^{2}}{r}+\varphi_{i j}(r)
$$

where $\mathrm{q}_{\mathrm{i}}$ and $\mathrm{q}_{\mathrm{j}}$ are the ionic charges, $\mathrm{r}$ is the inter-atomic distance, $\varphi_{\mathrm{ij}}$ is the short-range interaction term, which accounts for of the repulsion between electron clouds, van der Waals attraction, polarization effects and, when needed, bond terms.

For ionic or partially ionic materials the rigid ionic model which neglect the ionic polarizability is the most commonly used. However, the atomic polarizability can be explicitly accounted for by modelling polarizable atoms such as the oxide ions with core-shell dipoles, i.e. two opposite charges connected by a harmonic spring.[19]

Force fields, spatial (size of the box) and temporal (cooling procedure) dimensions of the MD simulation may have a considerable impact on the final atomic arrangement obtained[11]. Hence, the reliability of the structural model obtained is proved by the comparison with the experimental data.

\subsection{Ab-initio Molecular Dynamics.}

In ab-initio molecular dynamics (AI MD) the forces acting on the nuclei are computed from electronic structure calculations as the molecular dynamics trajectory is generated. The explicit treatment of electronic structure makes AI MD extremely useful, in terms of accuracy and predictability, for the study of systems difficult to parametrize, such as multi-coordination, and multi-oxidation states of species, reactivity at surfaces or dynamical processes in melts. 
However, the increased in computational costs is significant, thus only relatively small system size (100-300 atoms) and time (10-100 ps) are affordable via classical MD. Therefore, statistically sound descriptions of medium-range features in glasses containing more than four oxides are still not obtained by these methods.

\subsection{Mixed classical-AI MD procedure.}

The computational protocol usually adopted in first-principles simulations of glasses consists in using as a 'starting guess' an initial structure obtained through classical MD with an empirical potential. [6,20,21]. A partial relaxation of the structure is then carried out at the ab initio level. However, restrictions due to the high computational costs prevent a full relaxation at the medium-range order, which usually remains completely determined by the quality of the empirical potential used to construct the initial structure. Therefore, the scope of these mixed classical/ab initio approaches is limited to the investigation of properties with local character.[22-26]

\section{Structural descriptors for bioactivity prediction}

The short and medium range structure features of the glasses can be extracted from the tree-dimensional models obtained by MD simulations. Besides the bond length, bond angle distributions, and coordination geometries of the constituting ions, other important structural features at length scales beyond the first coordination shell affect the dissolution and the bioactive behaviour of the glass. In particular, the network connectivity, the coordination environment of network formers and network modifier cations, the tendency of cation to cluster and the formation of inhomogeneous regions [7,8,22,27], as well as the occurrence of chain and ring fragments[28], and the diffusion properties of modified cations[29]. Some of these structural descriptors used in almost all the papers reviewed in this chapter, are describe in the following paragraphs.

\subsection{The network connectivity}

The network connectivity (NC) of a glass is the most common structural descriptor used to predict the bioactivity[29]. NC depends critically on composition being defined as average number of bridging oxygen atoms per network former. In general, highly bioactive glasses are characterized by a low network connectivity $(\leq 2.5)$, denoting a fragmented silicate matrix, mainly constituted by linear polymer chains. In this case, the release of $-\mathrm{O}-[\mathrm{Si}-\mathrm{O}-]_{n}$ chains needed for biodegradation requires breaking a lower number of $\mathrm{Si}-\mathrm{O}$ bonds compared to highly ramified structure characterized by $\mathrm{Q}^{3}$ and $\mathrm{Q}^{4}$ silicate units ( $\mathrm{Q}$ designates 'quaternary' and $n$ the number of bridging oxygens (BO) connected to other network former cations.) 
(Figure 1a,c). The presence of hydroxyl groups in sol-gel glasses yields an actual NC lower than that calculated from the nominal composition [30].

$\mathrm{NC}$ as calculated from the nominal molecular formula only[29] is an average value and relies on two assumptions: a) the glass is homogeneous in nature; b) when a bridging oxygen has been replaced by two non-bridging oxygens, the bond is completely broken. However, a) in multicomponent glasses segregation of ions in specific region gives rise to heterogonous glasses (for example, fluorinated 45S5 bioglass presents silicate-rich and silicate-poor regions[31-33], and b) the disrupting effect on the network can vary depending on the type of modifier cation introduced (i.e. $\mathrm{Na}$ has a more disrupting effect compared to $\mathrm{Ca}$, which can also assume the intermediate role of charge compensator).

In this respect, $\mathrm{NC}$ computed by computer simulations as weighted average of the $\mathrm{Q}^{\mathrm{n}}$ distributions of network former ions is more appropriate. It is defined as:

$$
N C=\sum_{n=0}^{4} x_{n} \cdot n
$$

where $x_{n}$ is the percentage of the $\mathrm{Q}^{\mathrm{n}}$ species $(\mathrm{n}=0,1,2,3,4)$. It can be computed over all the three-dimensional model of the glass and/or in specific zones when mesoscale segregation of network occurs, and the real effect of cations with intermediate network-former/modifier character can be taken into account, as shown in the following paragraphs.

\subsubsection{Strength of the glass network}

A theoretical structural descriptor that estimates the degree of connectivity of the network and its overall strength $\left(\mathrm{F}_{\mathrm{net}}\right)$ has been derived to take into account the different energetics of the $\mathrm{X}-\mathrm{O}$ and $\mathrm{X}-\mathrm{F}$ bonds in fluorinated bioactive glasses[8,31]. $F_{\text {net }}$ is obtained by using the formula:

$$
F_{\text {net }}=\frac{1}{N}\left[\sum_{i}^{\text {cations }} \sum_{j}^{\text {anions }} n_{i} \cdot C N_{i j} \cdot B E_{i j} \cdot m_{i j}\right]
$$

where $\mathrm{N}$ is the total number of atoms, $\mathrm{n}_{\mathrm{i}}$ is the number of atoms of the $\mathrm{i}^{\text {th }}$ species; $\mathrm{CN}_{\mathrm{ij}}$ is the mean coordination number of ij pairs atoms ( $\mathrm{i}=\mathrm{Si}, \mathrm{P}, \mathrm{Zn}, \mathrm{Na}, \mathrm{Ca} ; \mathrm{j}=\mathrm{O}^{2-}$ , $\mathrm{F}^{-}$) whereas $\mathrm{BE}_{\mathrm{ij}}$ are the gas phase bond enthalpies. The multiplicative factor $\mathrm{m}_{\mathrm{ij}}$ represents the maximum number of $\mathrm{SiO}_{4}$ and $\mathrm{PO}_{4}$ units linked to the $\mathrm{i}-\mathrm{O}$ or $\mathrm{i}-\mathrm{F}$ bonds, and tunes the contribution of each bond to the overall network strength.

\subsubsection{Strength of modifier-mediated cross-link interactions}

It is generally assumed that the variation in the ion strength depends on the number of $\mathrm{O}-\mathrm{M}-\mathrm{O}$ inter tetrahedral connections.

Thus, an evaluation of the overall strength of modifiers which mediates crosslink interactions in the glass can be obtained from the MD structure, by combining 
the density of the inter-tetrahedral links $T$ formed by each modifier cation $\mathrm{M}$ with the corresponding $\mathrm{M}-\mathrm{O}$ ionic bond strength.[34,35]

In particular, a linear combination of the $\mathrm{NC}, \mathrm{T}$ and $\mathrm{R}_{\mathrm{M}-\mathrm{M}}$ (see next paragraph for definition) descriptors:

$$
s=\alpha \cdot N C+\beta \cdot R_{M-M}+\gamma \cdot T_{M}
$$

has been derived and used to understand the behavior of known compositions of yttrium-doped bioactive glasses, and extrapolate this insight to new potentially interesting compositions[36]

\subsection{Clustering of network and modifying cations}

Clustering effects have important consequences on ion mobility, repolymerization of the silica network, and crystallization tendency. Therefore these are key factors in biodegradation since they may inhibit or enhance leaching of the ions in the surrounding environment.

The ratio $\mathrm{R}_{\mathrm{X}-\mathrm{Y}}$ between the number ions of $\mathrm{Y}$ found around the coordination sphere of $X$ computed from the MD model and that expected from a homogeneous distribution of the $\mathrm{X}-\mathrm{Y}$ cations is a statistical measure of the tendency of the $\mathrm{X}$ and $\mathrm{Y}$ cations to cluster in the glass matrix. The ratio is computed such as $\mathrm{R}_{\mathrm{X}-\mathrm{Y}}=1$ indicates that the uniform distribution is respected (i.e. no clustering), while $R_{X-Y}$ $>1$ implies spatial clustering[37,38] If $\mathrm{X}=\mathrm{Y}$ self-aggregation is accounted for. An important issue that involve ion clustering is the pronounced devitrification tendency of bioglasses. The highly disrupted silicate network facilitates the rearrangement of the structural units to form critical size nuclei for crystallization. Partial crystallization will not necessarily reduce the bioactivity, depending on the crystal phases forming and the composition of the remaining glass phase[2]. A simple descriptor for predicting the crystals that could separate from glasses has been proposed[39,40]. Based on the assumption that the nucleating tendency depends on the structural similarity between the glass and its isochemical crystals, the algorithm analyzes the stoichiometry of different spherical regions in the bulk glass and it with the stoichiometry ratio of compositionally equivalent crystalline phases stored in a database.

\section{4. $\mathrm{SiO}_{2}$-based bioactive glass systems}

Silicate-based glasses exhibit bioactivity only over a relatively narrow range of compositions.

The 45S5 Bioglass $\left(46.1 \% \mathrm{SiO}_{2}, 24.4 \% \mathrm{Na}_{2} \mathrm{O}, 26.9 \% \mathrm{CaO}, 2.6 \% \mathrm{P}_{2} \mathrm{O}_{5}\right.$, in mol $\%$ ), was the first material able to form an interfacial bond with host tissue, when implanted in rats[41]. Kokubo and co-workers[42] demonstrated that also $\mathrm{P}_{2} \mathrm{O}_{5}$-free $\mathrm{Na}_{2} \mathrm{O}-\mathrm{CaO}-\mathrm{SiO}_{2}$ glasses are bioactive with the rate of formation of the biologically active apatite layer similar to that of 45S5 Bioglass. 
However, numerous recent investigations conducted both in vitro and in vivo reveal that the presence of $\mathrm{P}$ enhance the bioactivity[1]. The rate at which $\mathrm{Ca}, \mathrm{P}, \mathrm{Si}$ ions enter the fluid surrounding the glass[43], which is crucial for triggering the osteoblast activity, strongly depends on the amount of phosphate units into the glass. Moreover, the ion release also controls the local $\mathrm{pH}$ and the presence of $\mathrm{P}$ avoids excessive acidity that inhibits bone bonding[44].

\subsection{Structure of bioglass $45 \mathrm{~S} 5$}

The atomic structure of silica glasses is determined by the silica tetrahedra connected by $-\mathrm{Si}-\mathrm{O}-\mathrm{Si}-$ bridging oxygen bonds (Figure 1a). Silicon is therefore the glass network-forming atom. Network-modifying cations (e.g. alkali and alkaline-earth metal oxides) can disrupt the network by forming non-bridging oxygen (NBO) bonds such as $\mathrm{Si}-\mathrm{O}^{-} \mathrm{Na}^{+}$(Figure 1b).

The medium-range order around the network-forming cation is expressed as $\mathrm{Q}^{\mathrm{n}}$ species distribution where $\mathrm{Q}$ designates 'quaternary' and $n$ the number of BO oxygens connected to other network former cations ranges from 0 to 4 . (Figure 1c) $\mathrm{Q}^{\mathrm{n}}$ therefore provides a direct link to the polymerization degree of the structure. Thus, $\mathrm{Q}^{4}$ describes a three-dimensional network, $\mathrm{Q}^{3}$ - two-dimensional sheets, $\mathrm{Q}^{2}$ - chains and rings, $\mathrm{Q}^{1}$ and $\mathrm{Q}^{0}$ correspond to isolated dimers and tetrahedra, respectively.

The results of a pioneering MD-GIPAW[26] study on 45S5 bioactive glass clearly showed and confirmed that the host silica network is described by a trinomial $\mathrm{Q}^{\mathrm{n}}$ distribution consisting of chains and rings of $\mathrm{Q}^{2} \mathrm{Si}(67.2 \%) \mathrm{SiO}_{4}$ tetrahedra cross-linked with $\mathrm{Q}^{3} \mathrm{Si}(22.3 \%)$ species and terminated by a low quantity of $\mathrm{Q}^{1} \mathrm{Si}(10.1 \%)$ species[25] .

The structural role of phosphorus in bioglass has been debated for long and only recently been clarified. The controversy regarded its presence as orthophosphate units $\left(\mathrm{Q}^{0}\right)$, with charge balanced by sodium and/or calcium, $\left({ }^{31} \mathrm{P}\right.$ and $\left.{ }^{17} \mathrm{O} \mathrm{NMR}\right)$ or in mixed silicate/phosphate network containing $\mathrm{Si}-\mathrm{O}-\mathrm{P}$ bonds, and originated both by the results of NMR experiments[45-47] and theoretical studies.[12,25,27,48,49] It is now recognized that while the majority of phosphorus atoms are present as isolated orthophosphate tetrahedra, small amounts of $\mathrm{Si}-\mathrm{O}-\mathrm{P}$ bonds $(\sim 8 \%)$ are also present at high $\mathrm{P}_{2} \mathrm{O}_{5}$ content[50]. 

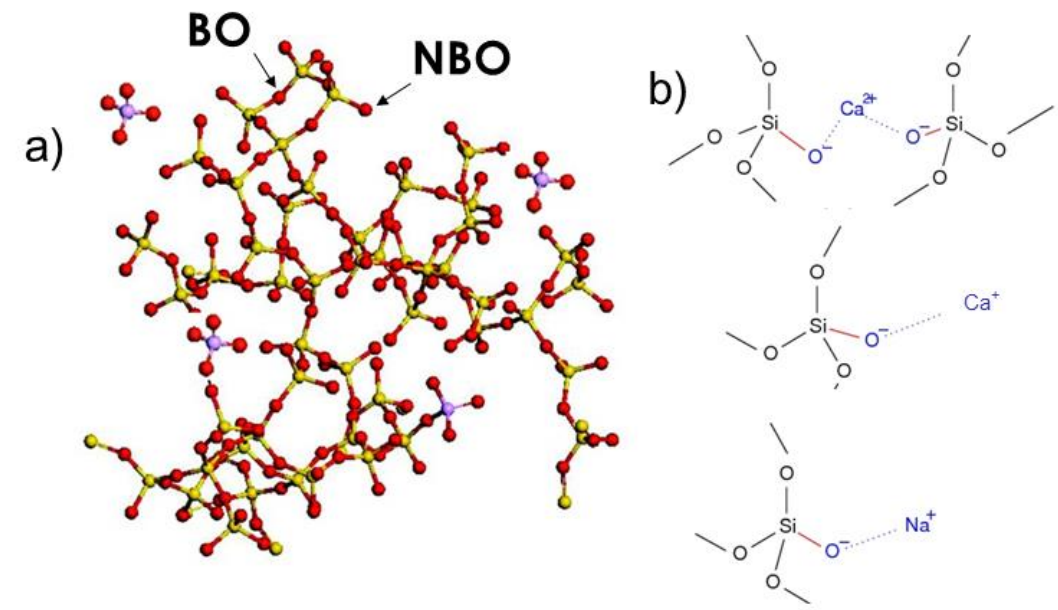

c)

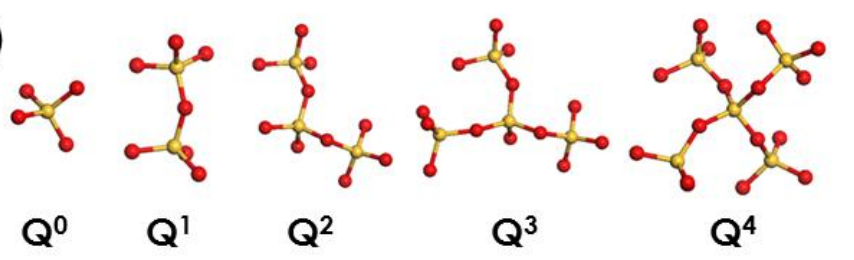

Figure 1. a) A fragment of branched network chain in 45S5 (modifiers have been removed for clarity) yellow ball: silicon; red ball: oxygen; purple ball: phosphorus; b) interaction of $\mathrm{Na}$ and $\mathrm{Ca}$ ions with the silicate network, and , c) three dimensional representations of the different $\mathrm{Q}^{\mathrm{n}}$ species (central atom). Figure 1a is adapted with permission from ref.[51], copyright 2011 American Chemical Society. Figure 1c is adapted with permission from ref.[26], copyright 2013 Royal Society of Chemistry.

These orthophosphate groups are surrounded by modifier cations for chargebalancing purposes, and it has recently be shown that the $\mathrm{P}$ atoms in short-range scale phosphosilicate glasses are randomly distributed in the glass. In particular, across a short-range scale inferior of $450 \mathrm{pm}$. The disperision of the phosphate-ions is independent on the degree of polymerization of silicate network and nearly independent of the $\mathrm{P}$ content of the glass in the range of 1-6 mol \% $\mathrm{P}_{2} \mathrm{O}_{5}$ [52].

While early MD simulation experiments[53,54] have reported different $\mathrm{Ca}$ and $\mathrm{Na}$ distributions in series of glasses with increased $\mathrm{P}_{2} \mathrm{O}_{5}$ content, a random distribution between the silicate rich regions and the phosphate rich regions of the glass structure seems to be preferred in the bioglass 45S5.[2,23,48,54].

A recent study carried out with a mixed computational (MD) and experimental (NMR) approach[55] has investigated the intermixing of network modifying $\mathrm{Na}^{+} / \mathrm{Ca}^{2+}$ ions around the silicate and phosphate tetrahedra in a wide series of soda lime phosphosilicate glasses, whose $\mathrm{P}$ content and silicate network connectivity were varied independently. The extent of $\mathrm{Na}^{+} / \mathrm{Ca}^{2+}$ ordering around a given $\mathrm{Q}^{\mathrm{n}}$ of $\mathrm{Si}$ or $\mathrm{P}$ computed by MD simulations indicates that $\mathrm{Na}$ and $\mathrm{Ca}$ ions intermixed nearly randomly. The overall weak preferences are essentially independent of the $\mathrm{Si}$ and $\mathrm{P}$ contents of the glass, but depend of the total amount of network modifiers. 
The most negatively charged $\mathrm{P} \mathrm{Q}^{0}$, and $\mathrm{Si} \mathrm{Q}^{1}$, and $\mathrm{Q}^{2}$ groups present in $45 \mathrm{~S} 5$ bioactive silicate glass, show the strongest preferences for the divalent $\mathrm{Ca}^{2+}$ cations, but this preference becomes less pronounced by increasing the total amount of network modifiers, whereas the preference of the lower-charged $\mathrm{P} \mathrm{Q}^{1}$ and $\mathrm{Si} \mathrm{Q}^{3}$ species for $\mathrm{Na}^{+}$cations increases.

Very recently, the structural features of a series of $45 \mathrm{~S} 5$ bioactive silicate glass derivatives spanning a wide range of $\mathrm{Na}, \mathrm{Ca}, \mathrm{Si}$, and $\mathrm{P}$ compositions has been reported[56]. The results from MD and NMR studies shown that it is possible to obtain both a rapid degradation of the glass network and fast dissolution of biologically active ions by a fine tuning of network connectivity and of the amounts of readily released orthophosphate ions. On this process, the propensity of $\mathrm{P}$ to be arranged in orthophosphate groups detached from the glass network is the key factor.

\subsection{The structure-property relationships of substituted bioactive glasses}

Over the last decade, research activity has been focused on adding modifier ions in bioactive glasses to increase their potential therapeutic benefit. A certain degree of flexibility in glass composition allows for addition of several elements in different concentrations [57], thus improving their physical-chemical properties for specific applications. For example, the strength, toughness, and elastic properties, which are a major bottleneck for the resistance of an implant against mechanic loads; high solubility may be the major disadvantage of bioglasses when used for long-term implants, since most of the released ions may be transported away from the region near the implant from the biological fluid prior to the formation of new bone.

However, the same property, high solubility, can be exploit to release specific ions with therapeutic action in the human body exactly at the site where they are needed, with minimized side effects. Furthermore, by controlling the rate of bioactive glasses dissolution through variation of the glass network connectivity and the type of modifier or intermediate ion, long term sustained therapeutic effects can be obtained [2].

In the following, we review the contribution of molecular simulations studies to the understanding of the composition-structure-property relationships obtained by several additive ions, such as magnesium $(\mathrm{Mg})$, strontium $(\mathrm{Sr})$, zinc ( $\mathrm{Zn})$, aluminum $(\mathrm{Al})$, gallium $(\mathrm{Ga})$, Cerium $(\mathrm{Ce})$ and fluoride $(\mathrm{F})$.

\subsubsection{Magnesium-bioactive glasses}

The replacement of $\mathrm{CaO}$ for $\mathrm{MgO}$ in glasses derived from the parent 45S5 Bioglass $\left(46.2 \mathrm{SiO}_{2} \cdot 24.3 \mathrm{Na}_{2} \mathrm{O} \cdot(26.9-x) \mathrm{CaO} \cdot 2.6 \mathrm{P}_{2} \mathrm{O}_{5} \cdot x \mathrm{MgO}\right.$ where $x=0,5,10$, 15,20 , and $26.9 \% \mathrm{~mol}$ ) produces significant changes on the structure, chemical durability, and elastic properties as detected by means of molecular dynamics simulations[35]. 
The results show that the $\mathrm{Mg}$ ions are mainly 5-fold coordinated; however, nonnegligible amount of 4- and a small amount of 6-fold coordinated species are also observed as a function of the $\mathrm{MgO}$ content.

The total number of NBOs in the glass is unchanged with respect to the 45S5 Bioglass, therefore the overall network connectivity (NC) with an open structure dominated by $\mathrm{Si}^{2}$ species is also similar. Differences are instead observed in the small number of shared edges between $\mathrm{MgO}_{5}$ and $\mathrm{SiO}_{4}$ polyhedra with respect to the $\mathrm{CaO}_{6}-\mathrm{SiO}_{4}$ ones. In fact, the higher field strength of $\mathrm{Mg}$ allows the coordination from NBOs belonging to different tetrahedra only. Thus, the larger rings formed improving the solubility and the melt viscosities of $\mathrm{Mg}$-containing silicate glasses.

Segregation of modifying cations is observed: $\mathrm{Na}$ and $\mathrm{Ca}$ are found in the phosphate rich regions, whereas $\mathrm{Na}, \mathrm{Ca}$, and $\mathrm{Mg}$ ions are homogeneously distributed in the silicate matrix. $\mathrm{Ca}$ and $\mathrm{Mg}$ manifest a clear preference for low-n $\mathrm{Q}$ silicate sites whereas the $\mathrm{Na}$ ions are preferably found around high-n sites. Therefore, an increasing of the $\mathrm{Na}$ leaching is expected because weaker interactions of sodium ions with bridging oxygens of high-n $\mathrm{Si} \mathrm{Q}^{\mathrm{n}}$ sites facilitate $\mathrm{Na}$ diffusion as reported for soda-lime glasses[58].

On these basis, the authors suggest that $\mathrm{MgO}$ content below $10 \mathrm{~mol} \%$ would improve the mechanical properties of bioglass 45S5, preserving good bioactivity.

The inserction of higher field strength $\mathrm{Mg}$ ions in alkali-free bioactive glasses also results in a decreasing in network connectivity. In this case, the expected increase in bioactivity was indeed confirmed by in vitro bio-mineralization activity[59].

\subsubsection{Strontium-bioative glasses}

The effect of the $\mathrm{SrO} / \mathrm{CaO}$ substitution on the glass structure and diffusion of a series of bioactive glasses was studied by Du and Xiang[51,60] using MD simulations. Although in biomedical applications the $\mathrm{SrO}$ concentration is usually below $5 \mathrm{~mol} \%$, a wide range of $\mathrm{Sr}$ concentrations was used to understand the strontium substitution effect: $46.1 \mathrm{SiO}_{2} \cdot 24.4 \mathrm{Na}_{2} \mathrm{O} \cdot(26.9-\mathrm{x}) \mathrm{CaO} \cdot 2.6 \mathrm{P}_{2} \mathrm{O}_{5} \cdot \mathrm{xSrO}$ with $\mathrm{x}=0,1,5,10,15,20$ and $26.9 \%$ mol. It was shown that the substitution does not considerably change the medium range structure although a linear increase of glass density and decrease of molar volume as a function of $\mathrm{Sr}$ addition was found. $\mathrm{Ca}$ and $\mathrm{Sr}$ ions were preferentially distributed around phosphorus ions. Therefore, the authors concluded that the enhanced dissolution rate in $\mathrm{Sr}$ containing glasses is mainly due to the increase of free volume and the non-local effect that weakens the silicon-oxygen network of these systems.

Ionic diffusion MD studies on three bioactive glass compositions (from 46 to $65 \mathrm{~mol}_{\%} \mathrm{SiO}_{2}$ and $5 \% \mathrm{~mol} \mathrm{SrO} / \mathrm{CaO}$ )[60] showed higher diffusion coefficient and lower diffusion energy barrier for sodium with respect to calcium and strontium 
(see Figure 2); the diffusion coefficient of modifier cations decreases significantly with the increasing of silica content. This phenomenon explains the observed decreased solubility and bioactivity in $\mathrm{SrO} / \mathrm{CaO}$ substituted bioactive glasses.

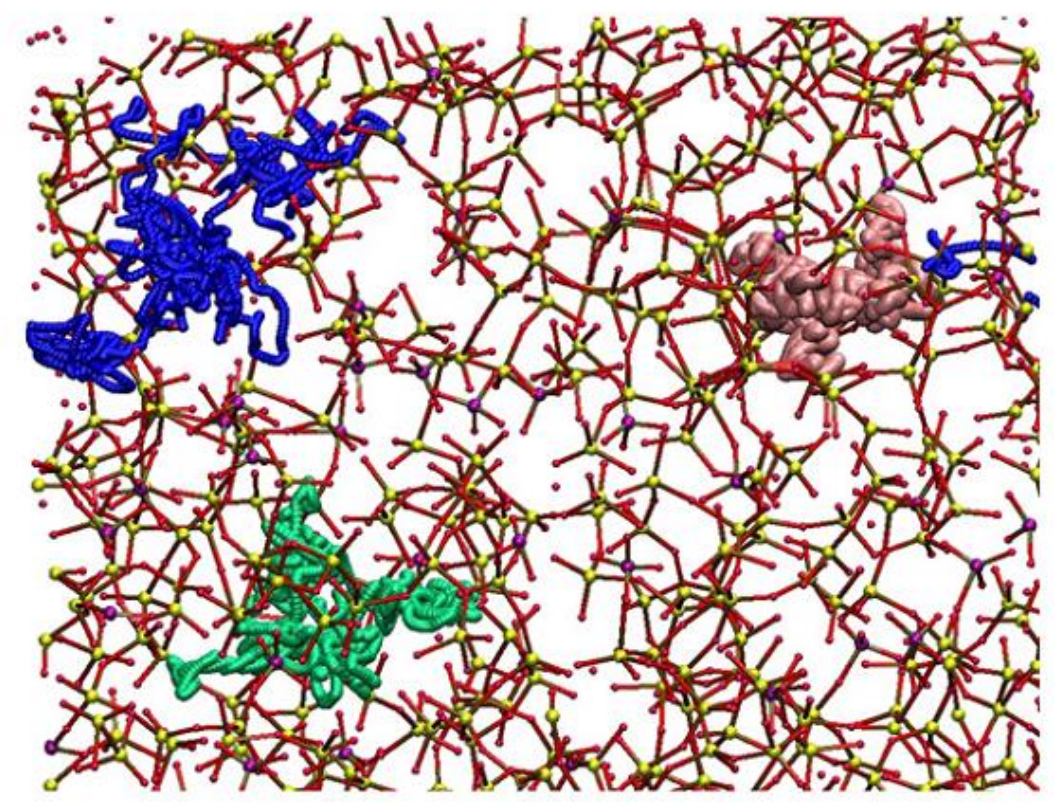

Figure 2. Diffusion pathways of three atoms: $\mathrm{Na}, \mathrm{Ca}$ and $\mathrm{Sr}$. Trajectories from MD simulations for $45 \mathrm{~S} 5-5 \mathrm{Sr}$ glass at $2000 \mathrm{~K}$ in the duration of 20 pico-seconds. Pink ball: Sr; blue ball: $\mathrm{Ca}$; green ball: $\mathrm{Na}$; small yellow ball: $\mathrm{Si}$; small purple ball: $\mathrm{P}$; small red ball: O. Figure is reprinted with permission from ref.[60], copyright 2012 Elsevier.

\subsubsection{Zinc-bioactive glasses}

Several MD studies devoted to the optimization of the $\mathrm{Zn}$ content on glasses based on the Bioglass 45S5 have been carried out in order to obtain glasses with preserved bioactivity and an optimal zinc oxide releasing rate[40,49,61-63]. These represent the first example of a complete cycle in rational glass design reported in the literature obtained by means of the Quantitative Structure-Property Relationships (QSPR) approach[8].

Two series of glasses, prepared by enriching the parent 45S5 bioglass with different percentages of $\mathrm{P}$ and/or $\mathrm{Zn}$ were analyzed:

$(2-\mathrm{y}) \mathrm{SiO}_{2} \cdot 1 \mathrm{Na}_{2} \mathrm{O} \cdot 1.1 \mathrm{CaO} \cdot \mathrm{yP}_{2} \mathrm{O}_{5} \cdot \mathrm{xZnO},(\mathrm{x}=0,0.13,0.62,0.78 ; \mathrm{y}=0.10,0.20$, $0,36 \% \mathrm{~mol})$. The salient feature that emerged is that $\mathrm{Zn}$ is always 4-fold coordinated and copolymerized with the $\mathrm{Si}$; producing a reinforced network with respect to the parent glass. Moreover, $\mathrm{Zn}$ favors the insertion of phosphorous into the network, progressively incorporating it into the network as zinc concentration increases. A highly ramified $\mathrm{Si}-\mathrm{Zn}-\mathrm{P}$ network is thus formed (see Figure 3) with 
a uniformly distribution of $\mathrm{Na}$ ions and segregation zones for the $\mathrm{Ca}$ ions in close proximity to $\mathrm{Si}$ and $\mathrm{P}$.

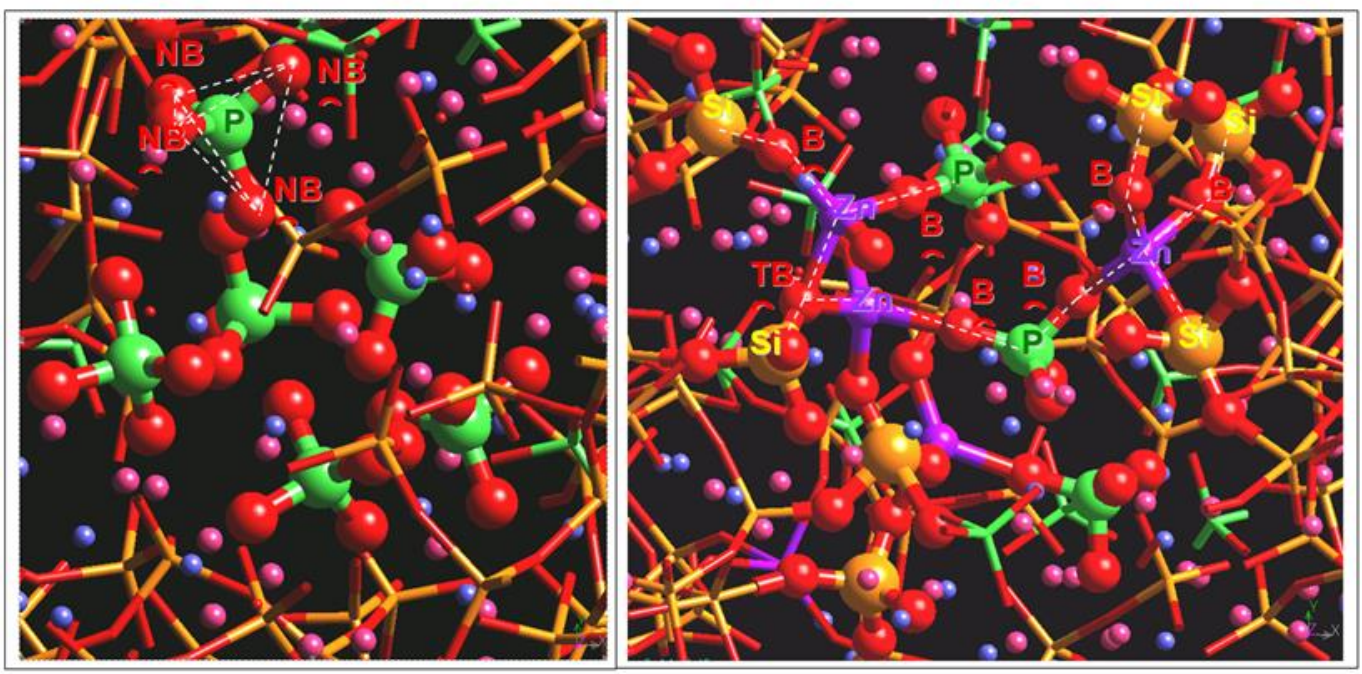

Figure 3. Snapshot of the simulated 45S5 (left) and HP5Z5 (right) glasses showing the zone rich in isolated $\mathrm{P}$ tetrahedra characteristic of the 45S5 bioglass and the $-\mathrm{Si}-\mathrm{Zn}-\mathrm{P}-\mathrm{Zn}-$ stings formed in HP5Z5. Si is represented in yellow, $\mathrm{Zn}$ in violet, $\mathrm{P}$ in green, $\mathrm{O}$ in red, $\mathrm{Na}$ in pink, and $\mathrm{Ca}$ in blue. Figure is reprinted with permission from ref.[49], copyright 2005 American Chemical Society.

These emerging picture explains the slow rate of $\mathrm{Zn}$ dissolution into the contacting media and the decrease in the overall reaction rate of the $\mathrm{Zn}$ containing glasses. In fact, the rapid exchange of $\mathrm{Na}^{+}$with $\mathrm{H}_{3} \mathrm{O}^{+}$ions present in the solution (first step of glass degradation), is hindered by the progressive reduction of suitable percolation channels for $\mathrm{Na}$ ions diffusion as a function of $\mathrm{Zn}$ addition. In addition, the $\mathrm{Na}$ ions mobility is also reduced by the strong electrostatic attraction of the $\left(\mathrm{ZnO}_{4}\right)^{2-}$ tetrahedra. Therefore, high concentrations of $\mathrm{Zn}$ seem to be responsible for the drastic reduction in the overall leaching activity of the glass and of its inability to form HA. To compensate these effects higher percentages of $\mathrm{P}_{2} \mathrm{O}_{5}$ with respect to the parent $45 \mathrm{~S} 5$ bioglass can be added.

HZ5 ( $x=0.16, y=0.0)$ and HP5Z5 ( $x=0.16, y=0.20)$ were chosen for further experimental studies on the basis of the results of the QSPR study. Chemical durability tests in water and in-vitro observations in a cellular medium[64,65] confirmed that the HP5Z5, but also the HP5Z10 ( $\mathrm{x}=0.32, \mathrm{y}=0.20)$ glasses manifest the pre-requisite for bioactivity, since they are able to form a HA layer on their surface after soaking in SBF solution. Moreover, the HZ5 and HP5Z5 glasses (not HP5Z10) were selected from cell culture tests with MC-3T3 osteoblast cells and related cytotoxicity tests as optimal compositions for cell adhesion and cell growth. Finally, in vivo experiments performed on HZ5[66] showed glass degradation processes and rates comparable to $45 \mathrm{~S} 5$. 


\subsubsection{Alkali-free Zinc bioactive glasses}

Insights on the structure of alkali-free bioactive glasses co-doped with strontium, magnesium and zinc have been gained by combining molecular dynamics simulations with solid-state nuclear magnetic resonance spectroscopy [67-69].

The results showed that the silicate network connectivity of $\mathrm{Zn}^{2+} / \mathrm{Mg}^{2+}$ and $\mathrm{Ca}^{2+/} \mathrm{Sr}^{2+}$ substituted glasses remains typical of highly bioactive compositions. This phenomenon is due to a similarity in coordination propensity of $\mathrm{Zn} / \mathrm{Mg}$ and $\mathrm{Ca} / \mathrm{Sr}$ : both $\mathrm{Zn}$ and $\mathrm{Mg}$ show a preference to be coordinated to $\sim 5 \mathrm{NBO}$ form $\mathrm{SiO}_{4}$ tetrahedra, whereas $\mathrm{Ca}$ and $\mathrm{Sr}$ are always coordinated to $\sim 6 \mathrm{NBOs}$ form $\mathrm{SiO}_{4}$ tetrahedra. Although an increase in the $\mathrm{Zn}^{2+} / \mathrm{Mg}^{2+}$ and $\mathrm{Ca}^{2+} / \mathrm{Sr}^{2+}$ ratios does not affect the network connectivity, the chemical degradation of the resulting glasses decreases, but no negative effect on the apatite-forming ability is observed.

The authors justified the lack of a straightforward correlation between the network connectivity and the dissolution behaviour by invoking a strategic role of the specific chemistry of ionic species in the glass, including valence and ionic radii.

\subsubsection{Fluoride-bioactive glasses}

Fluoride doped 45S5 bioactive glasses are used as dental biomaterials with enhanced biocompatibility, acidic resistance of enamel, and inhibition of alveolar cavities. Moreover, in these glasses flourapatite (FAp) production is preferred over the HCA, since FAp is chemically more stable and less dissolvable at low $\mathrm{pH}$ condition[70].

The release of ionic species (fluoride in particular) in the physiological environment is critical for the suitability of these glasses for biomedical applications, therefore a very accurate picture of the structural organization around fluorine is needed. The results obtained by several studies focused on the effect of fluorine addition to bioactive and other silicate glasses, are often contradictory. In particular, two questions have been deeply debated: what is the affinity of fluorine to silicon, and in the presence of more than one modifier species, how does fluorine prefer to bond to them?

Computational simulations carried out both by ab-initio and classical MD[31-33] and mixed computational simulations and NMR measurements[48] agree in depicting the same scenario of $\mathrm{F}$ almost exclusively coordinated to modifier cations $(\mathrm{Ca}$ and $\mathrm{Na}$ ) with no clear preference for either ion, and with coordination number close to 4 . Figure 4 reports the most common coordination environments found in Car-Parrinello MD simulations. [48] No appreciable amount of $\mathrm{Si}-\mathrm{F}$ bonds is detected, with only very few $(<2 \%)$ of such bonds observed in the glasses with the highest fluorine content. The most important characteristic of these systems is the marked affinity of fluoride to sodium and calcium which leads to the absence of $\mathrm{Si}-\mathrm{F}$ bonds. 

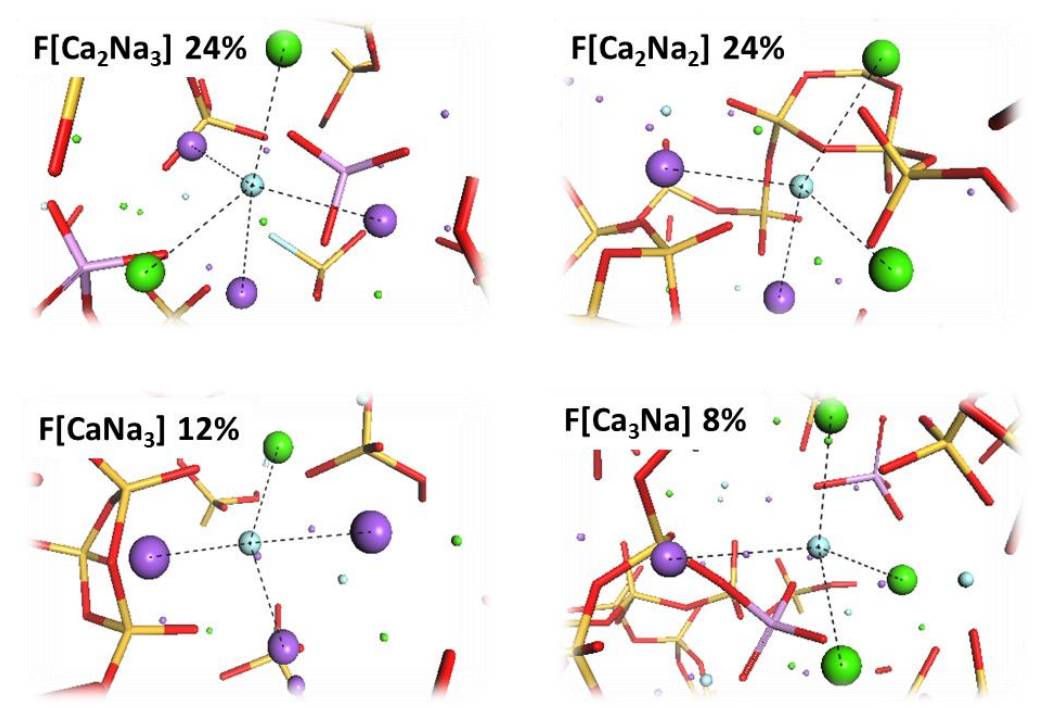

Figure 4. The most common fluorine environments found in fluorinated 45S5 bioglass. F, $\mathrm{Na}$ and $\mathrm{Ca}$ atoms are represented as cyan, violet and green spheres, respectively. $\mathrm{Si}$ and $\mathrm{O}$ atoms are represented as yellow and red sticks, respectively. Figure is adapted with permission from ref. [48], copyright 2012 Royal Society of Chemistry.

The segregation of ions into two separate regions (alkali-fluoride-rich and phospho-silicate-rich) leads to a network more polymerized with respect to the Ffree bioglass, with important consequences on the dissolution of $\mathrm{F}$ anions from the glass (Figure 5).

Since ion clustering in low-silica regions is associated with higher durability and lower bioactivity of glasses[71] this phenomenon can prevent or reduce the formation of the silica gel layer in fluorinated bioglass with significant differences in surface reactivity with respect to F-free 45S5 bioactive silicate glass[31,72]. 


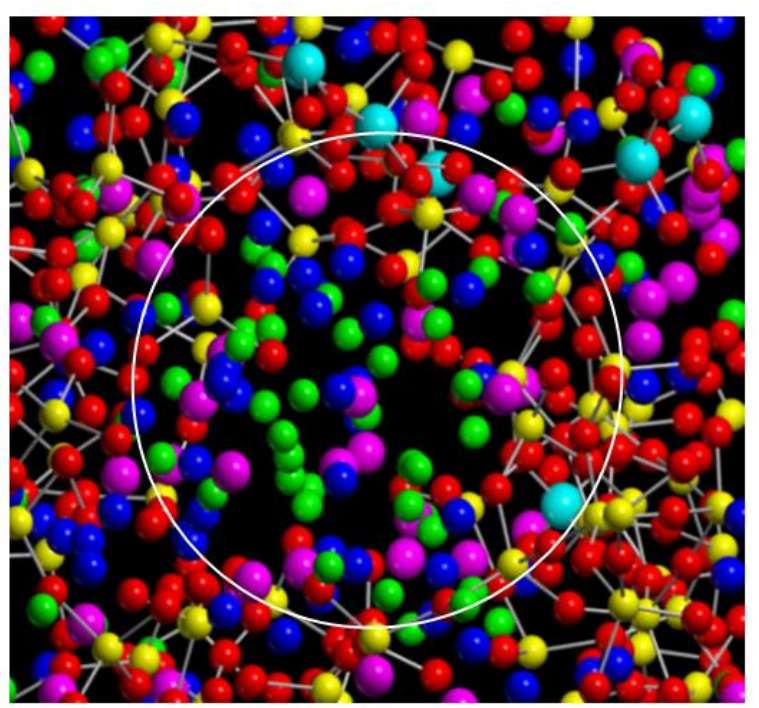

Figure 5. Snapshot of glass structure $\mathrm{HCaCaF}_{2} 15 \%$. In the white circle, is seen the microsegregation zone of $\mathrm{Ca}, \mathrm{Na}$ and fluorine ions. Green, blue, violet, cyan, yellow and red spheres represent F, Na, Ca, P, Si and O ions, respectively. Figure is reprinted with permission from ref.[33], copyright 2008 American Chemical Society.

\subsubsection{Gallium/Alluminum co-doped bioactive glasses}

Gallium is used for the cure of hypercalcemia associated with bone tumour metastasis. Moreover, $\mathrm{Ga}^{3+}$ can be introduced in biodegradable materials to prevent bacterial colonization after surgery, avoiding the systematic administration of antibiotics.[1]

The structural features of bioactive glasses co-doped with Gallium and Aluminum have been investigate by MD and compared with those of the original 45S5 Bioglass. [38] The three-dimensional model obtained for these glasses supports the interpretation of the experimental data and provides new insights into the different biological behaviours of $\mathrm{Ga}$ - and Al-containing phosphosilicate glasses. The 4-fold coordination is predominant for $\mathrm{Ga}$ whatever interatomic potential model is employed, but small amounts of 5- and 6-fold coordinated atoms have also been detected.

Therefore, the intermediate role of $\mathrm{Ga}$ in phosphosilicate glasses is supported, the network of Ga-containing glasses is less polymerized and more degradable than the corresponding ones doped with $\mathrm{Al}$ which, on the contrary, plays a network former role.

Small quantities of $\mathrm{Ga}$ or $\mathrm{Al}$ ions do not change drastically the medium range order characteristic of the 45S5 Bioglass. However, the clustering of $\mathrm{Ca}$ ions around phosphorus is more pronounced in Ga-doped to the Al-doped glasses. The formation of insoluble calcium phosphate domains (see Figure 6) leads to more durable glasses and together with the enhanced clustering of $\mathrm{Ca}$ ions observed for 
$\mathrm{Ga}$ and Al-doped bioactive glasses seems to emerge as a marker of non-bioactive behaviour.

In other words, the formation of inhomogeneous regions due to self-aggregation of the $\mathrm{Al}$ ions (phenomenon not observed for $\mathrm{Ga}$ ions) seems to inhibit the bioactivity; the authors furnished as a possible explanation a reduced mobility of phosphate groups associated with calcium ions in these segregation domains; as a consequence, the kinetics of dissolution is slower than that of the bioactive compositions in which isolated phosphates are embedded in a uniform environment.

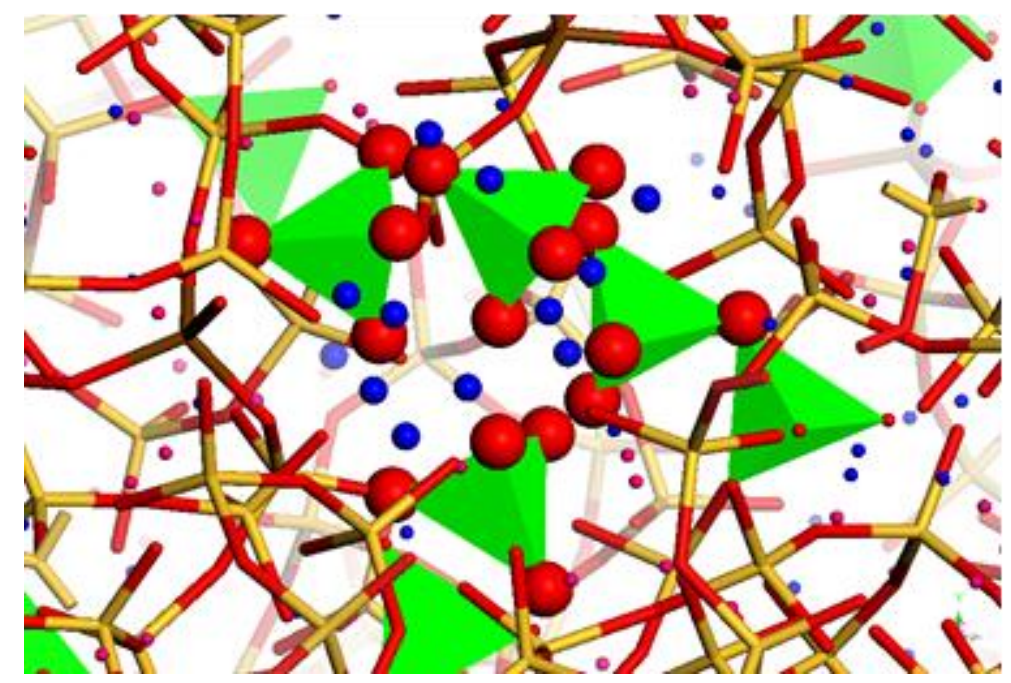

Figure 6. Example of calcium phosphate domain found in the Al-containing 45S5 bioglass. Phosphorous and oxygen atoms are represented in green tetrahedral and red balls, while calcium ions in blue spheres. Figure is reprinted with permission from ref.[38], copyright 2013 American Chemical Society.

\subsubsection{Cerium-bioactive glasses}

Recently, it has been reported that Ce-containing bioactive glasses are able to inhibit oxidative stress in terms of reduction of hydrogen peroxide by mimicking the catalase enzyme activity[73], and the relationship between structure and antioxidant and bioactivity properties has been investigated by means of MD simulations[73-75]. In fact, it is known that increasing of $\mathrm{CeO}_{2}$ content in the glass compositions enhances antioxidant ability at the expenses of bioactivity, since $\mathrm{CeO}_{2}$ delays the formation of the hydroxyapatite layer[76].

The results of computational simulations suggest that this behavior can be related to the medium-range order of the glass matrix. The preference of $\mathrm{Ce}$ ions to allocate close to phosphate domains could trigger several phenomena responsible of the retard in the release of phosphate ions from the glass network: a) entrap the phosphate ions in the glass network reducing the ion release, b) involve the phosphate ions in the formation of a stable, insoluble $\mathrm{CePO}_{4}$ crystalline phase 
observed by XRD analysis after thermal treatment of the glass samples, [76] and c) push the $\mathrm{Ca}$ ions in the silicate domains thus preventing the formation of calcium phosphate domains that can act as crystallization nuclei able to speed up the crystallization of $\mathrm{Ca}_{3}\left(\mathrm{PO}_{4}\right)_{2}$ on the glass surface.

Therefore, a good compromise between a high bioactivity level and an efficient catalase mimetic activity requires a proper adjustment of cerium oxide content in the glasses which results in $3.6 \%$ and $5.3 \%$ molar of $\mathrm{CeO}_{2}$ added to $45 \mathrm{~S} 5$ bioglass,

\section{Bioglass Nanoparticles and surface reactivity}

\subsection{Glass surface}

The open silicate network of bioactive glasses allows water molecules to penetrate the glass network much more easily than in more polymerized glasses.

Ab-initio or reactive force-field based studies are needed to describe the degradation behavior of a bioactive glass because of the formation of new bonds, defects and surface reconstruction that follows exposure of a glass surface. The size and time limits of these techniques due to computational costs prompted the researchers to verify carefully if the conclusions based on the bulk structure can be used to explain the phenomena that in practice take place predominantly on the surface.

The main findings regard the presence at the surface of relatively stable 2member rings, which are absent in the bulk of bioactive glasses, whose ring distribution is dominated by 4- and 5-membered sites[71,77]. Small rings form by linking two neighboring undercoordinated $\mathrm{Si}$ atoms with $\mathrm{Si}-\mathrm{O}$ dangling bonds, and represents one of the mechanisms by which unstable units are healed. Indeed, small rings on the 45S5 surface have been suggested as stable surface sites which are able to guide the nucleation of calcium phosphate on the surface[78,79].

The high stability of these rings on the surface of the 45S5 Bioglass was confirmed by AIMD simulations [80-82]. These simulations showed that some of these strained surface sites resist hydrolysis long enough to nucleate calcium phosphate precursors, which will then protect them from further reactions[71]. The simulations also suggested that the higher stability of small rings on the bioactive than the pure silica surface is also due to the presence of more favorable absorption sites for water like modifier cations ( $\mathrm{Na}$ and $\mathrm{Ca}$ ) and non-bridging oxygens [9].

\subsection{Bioglass Nanparticles}

Nanosized bioactive glass particles represent an attractive alternative to glass micro-sized particles for hard tissue regeneration. Their small size and large surface area lead to higher bioactivity, rapid remineralization, enhanced interaction with fibrinogen and cell proliferation, improved mechanical properties and dentin remineralisation rate. 
Classical MD simulations have shown to be useful to investigate the causes of the enhanced activity of nanosized samples of bioglasses[75,83]. The number of atoms contained, for instance, in an isolated 45S5 bioglass nanoparticle of 5-15 nm is of the order of $10^{4}-10^{5}$, a manageable size for classical MD simulations.

A comparison of the surface structure of a dry $45 \mathrm{~S} 5$ nanoparticle to that of a bulk sample exposing a flat surface has been reported recently[83].

The results show a key feature of bioactive glasses most beneficial for their bioactive behaviour such as high fragmentation of the silicate network is further enhanced on the surface of a 45S5 nanoparticle, compared to the bulk glass and to the virtually flat surface of a corresponding larger glass substrate. Moreover, the mobility of modifier cations and the density of small silicate rings - key features to support rapid dissolution and bone bonding processes at the surface - are also enhanced at the nanoparticle surface compared to samples of larger size.

Recently, classical MD simulations have been also used to investigate the different antioxidant properties of $\mathrm{Ce}$-containing bioactive glass nanoparticles with composition based on the Kokubo's and 45S5 glasses.[75] This investigation revealed that the different catalase mimetic activity of the two glass nanoparticles is related to the different $\mathrm{Ce}^{3+} / \mathrm{Ce}^{4+}$ ratio exposed at the glass surface. In particular, nanoparticles with a similar amount of cerium cations at the surface possess better antioxidant properties.

\section{6. $\mathrm{P}_{2} \mathrm{O}_{2}$-based bioglass systems}

Ternary phosphate glasses in the $\mathrm{CaO}-\mathrm{Na}_{2} \mathrm{O}-\mathrm{P}_{2} \mathrm{O}_{5}$ system represent another class of biodegradable glasses with a specific bioactivity controllable by varying the composition.[84] In fact, their degradation rates in aqueous solutions can vary from hours to several weeks. Furthermore, specific biological functions and enhanced biocompatibility can be induced by including specific dopants during the synthesis.[85-87]

As a result, phosphate glasses find a lot of applications in biomedicine, [84] such as in neural repair, tissue engineering [88] and bone fracture fixation[89] or as delivery systems for drugs, nutrients or antimicrobial agents.[90]

Compared to phospho-silicate bioactive glasses, there have been only few molecular dynamics simulations of phosphate based glasses in the $\mathrm{CaO}-\mathrm{Na}_{2} \mathrm{O}-\mathrm{P}_{2} \mathrm{O}_{5}$ system. One of the first investigation was reported by Tang et al.[91] who employed AIMD simulations to generate structural models of phosphate bioactive glasses with compositions $(\mathrm{CaO})_{\mathrm{x}}\left(\mathrm{Na}_{2} \mathrm{O}\right)_{0.55-\mathrm{x}}\left(\mathrm{P}_{2} \mathrm{O}_{5}\right)_{0.45}$ where $\mathrm{x}=0.30,0.35$, and 0.40 .

The structure of these glasses was dominated by $\mathrm{Q}^{2}$ and $\mathrm{Q}^{1}$ species, whereas the number of $\mathrm{Q}^{3}$ units, constituting the 3D phosphate network, significantly decreased with the calcium oxide content. The calculations revealed that the phosphate tetrahedral becomes more rigid with the concentration of calcium, which tend to be a stronger coordinator than sodium. Both modifiers were found to assume a pseudooctahedral environment with a coordination number of 6.6 and 6.9, respectively, independently on the composition. 
These structural models were then used to validate a new shell model classical force-field by Ainsworth et al.[92] that was later exploited to study the factors affecting the increased durability observed when $\mathrm{CaO}$ substitutes $\mathrm{Na}_{2} \mathrm{O}$ in larger models by the same authors. [93] They observed that $\mathrm{Q}^{\mathrm{n}}$ distribution and network connectivity of the investigated glasses did not change with the composition. The enhanced durability of these glasses when $\mathrm{Ca}$ substitutes $\mathrm{Na}$ are were interpreted by the tendency of calcium atoms to cross-link more phosphate chain and orthophosphate fragments with respect to sodium atoms. Figure 7 shows the binding of a sodium ion with three phosphate chains observed in their simulations.

Further, they showed that this increased cross-linking is a consequence of calcium's higher field strength than sodium that make it more prone to bind NBOs atoms than $\mathrm{Na}$ (6.2 vs 5.4). Because of these differences among the two modifier ions when the $\mathrm{Ca}$ content increases at the expense of the $\mathrm{Na}$ one the structure get more compact and the strengthening of the glass leads to the lower dissolution rates observed experimentally.

\subsection{Fluoride-bioactive glasses}

After having disclosed at the molecular level the relationships between the calcium and sodium content and the solubility of such glasses the same authors focused their attention on the investigation of the structural changes caused by the addition of fluorine[94] and silver ions.[95,96] Fluorinated phosphate glasses are interesting systems because they combine the bioactivity of phosphate glasses with the anti-cariogenic properties of fluoride. 


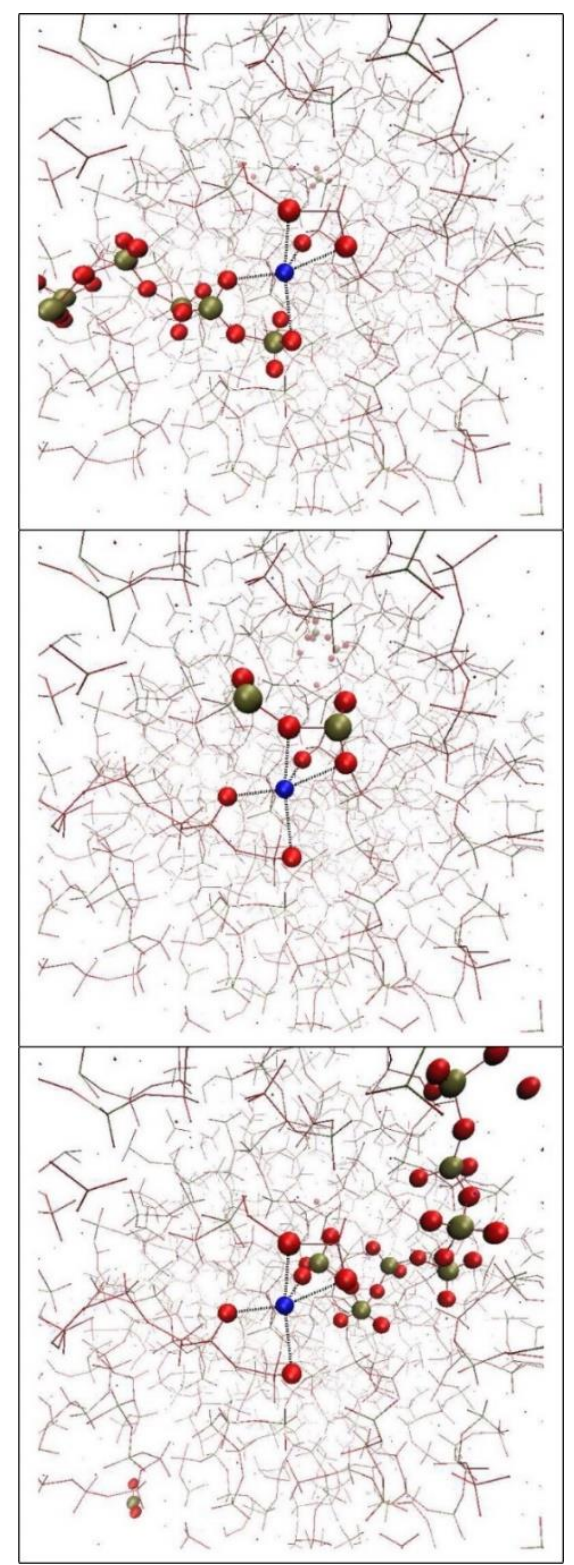

Figure 7. The picture shows a $\mathrm{Na}$ atom (blue sphere) bound to three phosphate fragments. Each picture shows a different phosphate chain bounded to the $\mathrm{Na}$ central ion. Figure is reprinted with permission from ref. [93], copyright 2013 American Chemical Society.

The incorporation of fluorine in phospho-silicate glasses has deleterious effects on the bioactivity because the silica rich layer formed at the glass surface that trigger the precipitation of calcium phosphate is less homogeneous on F-containing phosphosilicate glasses than on F-free phosphosilicate glasses, and in certain conditions is very thin or even absent.[72] This inhomogeneity was associated to the negligible amount of Si-F bonds in such glasses and to the separation of phosphosilicate-rich and $\mathrm{Na} / \mathrm{Ca} / \mathrm{F}-$ rich regions on medium range scales. $[31,33]$ 
Christie et al.[94] showed that in phosphate glasses there is a substantial amount of $\mathrm{P}-\mathrm{F}$ bonds with respect to the amount of $\mathrm{Si}-\mathrm{F}$ bonds in phosphosilicate glasses. Moreover, since the F-P coordination numbers is similar to the F-Na and F-Ca coordination numbers the mesoscale segregation observed in fluorinated phosphosilicate bioactive glasses is much less important in phosphate glasses. Since clustering of modifier atoms is associated with more durable and less bioactive glasses,[37] fluorinated phosphate glasses should be more bioactive than the phosphosilicate counterparts. Christie et al. showed that when fluorine bonds to phosphorous the tetrahedral structure of the latter is preserved since $\mathrm{F}$ replaces one of the oxygen atoms in a $\mathrm{P}-\mathrm{O}$ bond. Moreover, since bridging oxygens are replaced by non-bridging $\mathrm{F}$ ions with fluoride addition a slight decrease in the network connectivity with $\mathrm{F}$ content was also observed.

Finally, based on their AIMD simulations, they concluded that fluorinated phosphate glasses are a better alternative to Fluorinated phosphosilicate glasses since the incorporation of fluorine does not cause structural changes that would affect their bioactivity.

\subsection{Silver-bioactive glasses}

Another ion incorporated in phosphate-based bioactive glasses is silver that is known to have biocidal effects and thus can be incorporated to prevent or cure infections that can occur at the prosthesis interface once implanted in the body.[97] Ag-doped phosphate glasses has a wide range of bactericidal activity against a lot of bacteria[98] thanks to the involvement of the $\mathrm{Ag}^{+}$ions on the respiratory chain processes of bacteria and since it reduces the integrity of bacterial membranes.[99]

Experimentally, it was observed that the enhancement of $\mathrm{Ag}$ concentration in glasses of composition $\left(\mathrm{P}_{2} \mathrm{O}_{5}\right)_{0.5}(\mathrm{CaO})_{0.30}\left(\mathrm{Na}_{2} \mathrm{O}\right)_{0.20-\mathrm{x}}(\mathrm{Ag})_{\mathrm{x}}(\mathrm{x}=0.00-0.05)$ reduces the glass dissolution, silver ion release and the bactericidal activity.[100] Therefore, this activity leans on a continuous provision of silver in solution, which in turn depends on the bulk and surface structure as well as ionic diffusion and kinetic of dissolution.

A first attempt to understanding the dissolution phenomena in silver-doped phosphate glasses, from first-principles and classical MD simulations, was done by Ainsworth et al.[95] They investigated the short- and medium-range structure of phosphate glasses with varying amount of $\mathrm{Na}$ and ca ions and from 0 to $20 \mathrm{~mol} \%$ of $\mathrm{Ag}_{2} \mathrm{O}$, and tried to correlate the structural changes caused by the incorporation of silver into the glass.

They found that $\mathrm{Ag}$ ions have negligible effect on short range order of phosphorous. In these glasses Ag plays a network modifier role and was found to assume a distorted octahedral and trigonal bipyramidal geometry with about 5.5 oxygens and bond lengths of $2.5 \AA$. A disproportionation reaction $\left(2 \mathrm{Q}^{2}-\mathrm{Q}^{1}+\mathrm{Q}^{3}\right)$ was observed upon when silver ions replaced $\mathrm{CaO}$, but not on silver-doping via $\mathrm{Na}_{2} \mathrm{O}$ substitution. Since the network connectivity and the number of phosphate chains bounded to silver and sodium is was roughly the same,[96] they associated 
the increased durability of glasses in which silver replaces sodium to the differences between le local bonding of the two ions.

\section{Final remarks}

In the last decade, both classical and ab initio MD simulations have been successfully employed to shed light on the structure and properties of silicate, phosphosilicate and phosphate glasses. In this brief overview, we have showed how such techniques have been applied to investigate the structure-bioactivity relationships and to rationalize the effect of the inclusion of several doping ions on the structure and properties of bioactive glasses.

Albeit a lot of progresses have been achieved in the last years to better understand key steps related to the dissolution processes and to design new active compositions with specific properties some improvements in the computational procedures have to be reached. Some challenges remain especially for the production of reliable surface structures of bioactive glasses with different compositions and these must be coupled with a proper investigation of the surfacewater interactions as a function of simulation time. The investigation of the affinity between bioactive nanoparticles and blood plasma proteins will be of primary importance to have information on the fate of glass nanoparticles with specific medical properties once injected in the blood stream. However, because of the prohibitive space and time scales that must be spanned the possibility of using coarse grain MD simulations must be exploited. Moreover, since in the dentistry field glass ceramics are mixed with polymeric materials to produce hybrid matrices known as glass ionomer cements future promising directions will be to simulate such systems and their mechanical properties.

Despite these challenges, MD simulations is (and will be) certainly a powerful tool for scientists engaged in the research of new bioactive glass compositions.

\section{References.}

1. Jones JR. Review of bioactive glass: From Hench to hybrids. Acta Biomater. 2013;9:4457-86.

2. Brauer DS. Bioactive Glasses - Structure and Properties. Angew. Chem. Int. Ed. 2015;54:4160-81.

3. Hench LL. Bioceramics. J. Am. Ceram. Soc. 1998;81:1705-28.

4. Martin RA, Yue S, Hanna JV, Lee PD, Newport RJ, Smith ME, et al. Characterizing the hierarchical structures of bioactive sol-gel silicate glass and hybrid scaffolds for bone regeneration. Philos. Transact. A Math. Phys. Eng. Sci. 2012;370:1422-43. 
5. Pedone A. Properties Calculations of Silica-Based Glasses by Atomistic Simulations Techniques: A Review. J. Phys. Chem. C. 2009;113:20773-84.

6. Malavasi G, Menziani MC, Pedone A, Civalleri B, Corno M, Ugliengo P. A computational multiscale strategy to the study of amorphous materials. Theor. Chem. Acc. 2007;117:933-42.

7. Malavasi G, Pedone A, Menziani MC. Towards a quantitative rationalization of multicomponent glass properties by means of molecular dynamics simulations. Mol. Simul. 2006;32:1045-55.

8. Pedone A, Menziani MC. Computational Modeling of Silicate Glasses: A Quantitative Structure-Property Relationship Perspective. In: Massobrio C, Du J, Bernasconi M, Salmon PS, editors. Mol. Dyn. Simul. Disord. Mater. [Internet]. Springer International Publishing; 2015 [cited 2015 Aug 24]. p. 113-35. Available from: http://link.springer.com/chapter/10.1007/978-3-319-15675-0_5

9. Tilocca A. Rationalizing the Biodegradation of Glasses for Biomedical Applications Through Classical and Ab-initio Simulations. In: Massobrio C, Du J, Bernasconi M, Salmon PS, editors. Mol. Dyn. Simul. Disord. Mater. [Internet]. Springer International Publishing; 2015 [cited 2015 Aug 24]. p. 255-73. Available from: http://link.springer.com/chapter/10.1007/978-3-319-15675-0_10

10. Tilocca A. Current challenges in atomistic simulations of glasses for biomedical applications. Phys. Chem. Chem. Phys. 2014;16:3874-80.

11. Du J. Challenges in Molecular Dynamics Simulations of Multicomponent Oxide Glasses. In: Massobrio C, Du J, Bernasconi M, Salmon PS, editors. Mol. Dyn. Simul. Disord. Mater. [Internet]. Springer International Publishing; 2015 [cited 2015 Aug 24]. p. 157-80. Available from: http://link.springer.com/chapter/10.1007/978-3-319-15675-0_7

12. Tilocca A. Structural models of bioactive glasses from molecular dynamics simulations. Proc. R. Soc. Lond. Math. Phys. Eng. Sci. 2009;rspa.2008.0462.

13. Cormack AN, Tilocca A. Structure and biological activity of glasses and ceramics. Philos. Transact. A Math. Phys. Eng. Sci. 2012;370:1271-80.

14. Allen MP, Tildesley DJ. Computer simulation of liquids. Clarendon Press; 1987.

15. Pedone A, Corno M, Civalleri B, Malavasi G, Menziani MC, Segre U, et al. An ab initio parameterized interatomic force field for hydroxyapatite. J. Mater. Chem. 2007;17:2061-8. 
16. Pedone A, Malavasi G, Menziani MC, Cormack AN, Segre U. A new selfconsistent empirical interatomic potential model for oxides, silicates, and silicabased glasses. J. Phys. Chem. B. 2006;110:11780-95.

17. Tilocca A, de Leeuw NH, Cormack AN. Shell-model molecular dynamics calculations of modified silicate glasses. Phys. Rev. B. 2006;73:104209.

18. Tilocca A. Short- and medium-range structure of multicomponent bioactive glasses and melts: An assessment of the performances of shell-model and rigid-ion potentials. J. Chem. Phys. 2008;129:084504.

19. Yu H, van Gunsteren WF. Accounting for polarization in molecular simulation. Comput. Phys. Commun. 2005;172:69-85.

20. Ispas S, Benoit M, Jund P, Jullien R. Structural and electronic properties of the sodium tetrasilicate glass $\mathrm{Na} 2 \mathrm{Si} 4 \mathrm{O} 9$ from classical and ab initio molecular dynamics simulations. Phys. Rev. B. 2001;64:214206.

21. Tilocca A, Leeuw NH de. Structural and electronic properties of modified sodium and soda-lime silicate glasses by Car-Parrinello molecular dynamics. J. Mater. Chem. 2006;16:1950-5.

22. Tilocca A, de Leeuw NH. Ab Initio Molecular Dynamics Study of 45S5 Bioactive Silicate Glass. J. Phys. Chem. B. 2006;110:25810-6.

23. Corno M, Pedone A, Dovesi R, Ugliengo P. B3LYP simulation of the full vibrational spectrum of $45 \mathrm{~S} 5$ bioactive silicate glass compared to nu-silica. Chem. Mater. 2008;20:5610-21.

24. Corno M, Pedone A. Vibrational features of phospho-silicate glasses: Periodic B3LYP simulations. Chem. Phys. Lett. 2009;476:218-22.

25. Pedone A, Charpentier T, Malavasi G, Menziani MC. New Insights into the Atomic Structure of 45S5 Bioglass by Means of Solid-State NMR Spectroscopy and Accurate First-Principles Simulations. Chem. Mater. 2010;22:5644-52.

26. Charpentier T, Menziani MC, Pedone A. Computational simulations of solid state NMR spectra: a new era in structure determination of oxide glasses. Rsc Adv. 2013;3:10550-78.

27. Tilocca A, Cormack AN, de Leeuw NH. The Structure of Bioactive Silicate Glasses: New Insight from Molecular Dynamics Simulations. Chem. Mater. 2007;19:95-103. 
28. Tilocca A, Cormack AN, Leeuw NH de. The formation of nanoscale structures in soluble phosphosilicate glasses for biomedical applications: MD simulations. Faraday Discuss. 2007;136:45-55.

29. Hill RG, Brauer DS. Predicting the bioactivity of glasses using the network connectivity or split network models. J. Non-Cryst. Solids. 2011;357:3884-7.

30. Malavasi G, Menabue L, Menziani MC, Pedone A, Salinas AJ, Vallet-Regi M. New insights into the bioactivity of $\mathrm{SiO} 2-\mathrm{CaO}$ and $\mathrm{SiO} 2-\mathrm{CaO}-\mathrm{P} 2 \mathrm{O} 5$ sol-gel glasses by molecular dynamics simulations. J. Sol-Gel Sci. Technol. 2013;67:208-19.

31. Lusvardi G, Malavasi G, Tarsitano F, Menabue L, Menziani MC, Pedone A. Quantitative Structure-Property Relationships of Potentially Bioactive Fluoro Phospho-silicate Glasses. J. Phys. Chem. B. 2009;113:10331-8.

32. Christie JK, Pedone A, Menziani MC, Tilocca A. Fluorine Environment in Bioactive Glasses: ab Initio Molecular Dynamics Simulations. J. Phys. Chem. B. 2011;115:2038-45.

33. Lusvardi G, Malavasi G, Cortada M, Menabue L, Menziani MC, Pedone A, et al. Elucidation of the structural role of fluorine in potentially bioactive glasses by experimental and computational investigation. J. Phys. Chem. B. 2008;112:127309.

34. Christie JK, Tilocca A. Integrating biological activity into radioisotope vectors: molecular dynamics models of yttrium-doped bioactive glasses. J. Mater. Chem. 2012;22:12023-31.

35. Pedone A, Malavasi G, Menziani MC. Computational Insight into the Effect of $\mathrm{CaO} / \mathrm{MgO}$ Substitution on the Structural Properties of Phospho-Silicate Bioactive Glasses. J. Phys. Chem. C. 2009;113:15723-30.

36. Christie JK, Tilocca A. Molecular Dynamics Simulations and Structural Descriptors of Radioisotope Glass Vectors for In Situ Radiotherapy. J. Phys. Chem. B. 2012;116:12614-20.

37. Christie JK, Tilocca A. Aluminosilicate Glasses As Yttrium Vectors for in situ Radiotherapy: Understanding Composition-Durability Effects through Molecular Dynamics Simulations. Chem. Mater. 2010;22:3725-34.

38. Malavasi G, Pedone A, Menziani MC. Study of the Structural Role of Gallium and Aluminum in 45S5 Bioactive Glasses by Molecular Dynamics Simulations. J. Phys. Chem. B. 2013;117:4142-50. 
39. Lusvardi G, Malavasi G, Menabue L, Menziani MC, Pedone A, Segre U. A computational tool for the prediction of crystalline phases obtained from controlled crystallization of glasses. J. Phys. Chem. B. 2005;109:21586-92.

40. Malavasi G, Lusvardi G, Pedone A, Menziani MC, Dappiaggi M, Gualtieri A, et al. Crystallization kinetics of bioactive glasses in the $\mathrm{ZnO}-\mathrm{Na} 2 \mathrm{O}-\mathrm{CaO}-\mathrm{SiO} 2$ system. J. Phys. Chem. A. 2007;111:8401-8.

41. Hench LL, Splinter RJ, Allen WC, Greenlee TK. Bonding mechanisms at the interface of ceramic prosthetic materials. J. Biomed. Mater. Res. 1971;5:117-41.

42. Kokubo T. Surface chemistry of bioactive glass-ceramics. J. Non-Cryst. Solids. 1990;120:138-51.

43. Xynos ID, Edgar AJ, Buttery LD, Hench LL, Polak JM. Gene-expression profiling of human osteoblasts following treatment with the ionic products of Bioglass 45S5 dissolution. J. Biomed. Mater. Res. 2001;55:151-7.

44. Karlsson KH, Fröberg K, Ringbom T. A structural approach to bone adhering of bioactive glasses. J. Non-Cryst. Solids. 1989;112:69-72.

45. Hill R. An alternative view of the degradation of bioglass. J. Mater. Sci. Lett. 1996;15:1122-5.

46. Lockyer MWG, Holland D, Dupree R. NMR investigation of the structure of some bioactive and related glasses. J. Non-Cryst. Solids. 1995;188:207-19.

47. Elgayar I, Aliev AE, Boccaccini AR, Hill RG. Structural analysis of bioactive glasses. J. Non-Cryst. Solids. 2005;351:173-83.

48. Pedone A, Charpentier T, Menziani MC. The structure of fluoride-containing bioactive glasses: new insights from first-principles calculations and solid state NMR spectroscopy. J. Mater. Chem. 2012;22:12599-608.

49. Linati L, Lusvardi G, Malavasi G, Menabue L, Menziani MC, Mustarelli P, et al. Qualitative and Quantitative Structure-Property Relationships Analysis of Multicomponent Potential Bioglasses. J. Phys. Chem. B. 2005;109:4989-98.

50. Fayon F, Duée C, Poumeyrol T, Allix M, Massiot D. Evidence of NanometricSized Phosphate Clusters in Bioactive Glasses As Revealed by Solid-State 31P NMR. J. Phys. Chem. C. 2013;117:2283-8.

51. Xiang Y, Du J. Effect of Strontium Substitution on the Structure of 45S5 Bioglasses. Chem. Mater. 2011;23:2703-17. 
52. Stevensson B, Mathew R, Edén M. Assessing the Phosphate Distribution in Bioactive Phosphosilicate Glasses by 31P Solid-State NMR and Molecular Dynamics Simulations. J. Phys. Chem. B. 2014;118:8863-76.

53. Tilocca A, Cormack AN. Structural Effects of Phosphorus Inclusion in Bioactive Silicate Glasses. J. Phys. Chem. B. 2007;111:14256-64.

54. Linati L, Lusvardi G, Malavasi G, Menabue L, Menziani MC, Mustarelli P, et al. Medium-range order in phospho-silicate bioactive glasses: Insights from MASNMR spectra, chemical durability experiments and molecular dynamics simulations. J. Non-Cryst. Solids. 2008;354:84-9.

55. Mathew R, Stevensson B, Edén M. Na/Ca Intermixing around Silicate and Phosphate Groups in Bioactive Phosphosilicate Glasses Revealed by Heteronuclear Solid-State NMR and Molecular Dynamics Simulations. J. Phys. Chem. B. 2015;119:5701-15.

56. Mathew R, Stevensson B, Tilocca A, Edén M. Toward a Rational Design of Bioactive Glasses with Optimal Structural Features: Composition-Structure Correlations Unveiled by Solid-State NMR and MD Simulations. J. Phys. Chem. B. $2014 ; 118: 833-44$.

57. Hoppe A, Güldal NS, Boccaccini AR. A review of the biological response to ionic dissolution products from bioactive glasses and glass-ceramics. Biomaterials. 2011;32:2757-74.

58. Pedone A, Malavasi G, Menziani MC, Segre U, Cormack AN. Role of magnesium in soda-lime glasses: insight into structural, transport, and mechanical properties through computer simulations. J. Phys. Chem. C. 2008;112:11034-41.

59. Kapoor S, Semitela Â, Goel A, Xiang Y, Du J, Lourenço AH, et al. Understanding the composition-structure-bioactivity relationships in diopside $\left(\mathrm{CaO} \cdot \mathrm{MgO} \cdot 2 \mathrm{SiO}_{2}\right)$-tricalcium phosphate $\left(3 \mathrm{CaO} \cdot \mathrm{P}_{2} \mathrm{O}_{5}\right)$ glass system. Acta Biomater. 2015;15:210-26.

60. Du J, Xiang Y. Effect of strontium substitution on the structure, ionic diffusion and dynamic properties of 45S5 Bioactive glasses. J. Non-Cryst. Solids. 2012;358:1059-71.

61. Lusvardi G, Malavasi G, Menabue L, Menziani MC. Synthesis, Characterization, and Molecular Dynamics Simulation Of Na2O-CaO-SiO2- $\mathrm{ZnO}$ Glasses. J. Phys. Chem. B. 2002;106:9753-60.

62. Lusvardi G, Malavasi G, Menabue L, Menziani MC. A Combined Experimental-Computational Strategy for the Design, Synthesis and 
Characterization of Bioactive Zinc-Silicate Glasses. Key Eng. Mater. 2008;377:211-24.

63. Lusvardi G, Malavasi G, Menabue L, Menziani MC, Pedone A, Segre U. Density of multicomponent silica-based potential bioglasses: Quantitative structure-property relationships (QSPR) analysis. J. Eur. Ceram. Soc. 2007;27:499504.

64. Lusvardi G, Malavasi G, Menabue L, M.C.Menziani, Segre U, Carnasciali MM, et al. A combined experimental and computational approach to (Na2O) $1-\mathrm{x} \cdot \mathrm{CaO}$ - $(\mathrm{ZnO}) \mathrm{x}$ - 2SiO2 glasses characterization. J. Non-Cryst. Solids. 2004;345346:710-4.

65. Lusvardi G, Malavasi G, Menabue L, Menziani MC, Pedone A, Segre U, et al. Properties of zinc releasing surfaces for clinical applications. J. Biomater. Appl. 2008;22:505-26.

66. Lusvardi G, Zaffe D, Menabue L, Bertoldi C, Malavasi G, Consolo U. In vitro and in vivo behaviour of zinc-doped phosphosilicate glasses. Acta Biomater. 2009;5:419-28.

67. Goel A, Kapoor S, Tilocca A, Rajagopal RR, Ferreira JMF. Structural role of zinc in biodegradation of alkali-free bioactive glasses. J. Mater. Chem. B. 2013;1:3073-82.

68. Xiang Y, Du J, Skinner LB, Benmore CJ, Wren AW, Boyd DJ, et al. Structure and diffusion of $\mathrm{ZnO}-\mathrm{SrO}-\mathrm{CaO}-\mathrm{Na} 2 \mathrm{O}-\mathrm{SiO} 2$ bioactive glasses: a combined high energy X-ray diffraction and molecular dynamics simulations study. RSC Adv. 2013;3:5966-78.

69. Kapoor S, Goel A, Tilocca A, Dhuna V, Bhatia G, Dhuna K, et al. Role of glass structure in defining the chemical dissolution behavior, bioactivity and antioxidant properties of zinc and strontium co-doped alkali-free phosphosilicate glasses. Acta Biomater. 2014;10:3264-78.

70. Rabiee SM, Nazparvar N, Azizian M, Vashaee D, Tayebi L. Effect of ion substitution on properties of bioactive glasses: A review. Ceram. Int. 2015;41:7241-51.

71. Tilocca A. Models of structure, dynamics and reactivity of bioglasses: a review. J. Mater. Chem. 2010;20:6848-58.

72. Lusvardi G, Malavasi G, Menabue L, Aina V, Morterra C. Fluoride-containing bioactive glasses: Surface reactivity in simulated body fluids solutions. Acta Biomater. 2009;5:3548-62. 
73. Nicolini V, Gambuzzi E, Malavasi G, Menabue L, Menziani MC, Lusvardi G, et al. Evidence of Catalase Mimetic Activity in $\mathrm{Ce} 3+/ \mathrm{Ce} 4+$ Doped Bioactive Glasses. J. Phys. Chem. B. 2015;119:4009-19.

74. Nicolini V, Varini E, Malavasi G, Menabue L, Menziani MC, Lusvardi G, et al. The effect of composition on structural, thermal, redox and bioactive properties of Ce-containing glasses. Mater. Des. 2016;97:73-85.

75. Pedone A, Muniz-Miranda F, Tilocca A, Menziani MC. The antioxidant properties of Ce-containing bioactive glass nanoparticles explained by Molecular Dynamics simulations. Biomed. Glas. 2016;2:19-28.

76. Leonelli C, Lusvardi G, Malavasi G, Menabue L, Tonelli M. Synthesis and characterization of cerium-doped glasses and in vitro evaluation of bioactivity. J. Non-Cryst. Solids. 2003;316:198-216.

77. Berardo E, Pedone A, Ugliengo P, Corno M. DFT Modeling of $45 \mathrm{~S} 5$ and 77S Soda-Lime Phospho-Silicate Glass Surfaces: Clues on Different Bioactivity Mechanism. Langmuir. 2013;29:5749-59.

78. Sahai N, Anseau M. Cyclic silicate active site and stereochemical match for apatite nucleation on pseudowollastonite bioceramic-bone interfaces. Biomaterials. 2005;26:5763-70.

79. Bolis V, Busco C, Aina V, Morterra C, Ugliengo P. Surface Properties of SilicaBased Biomaterials: Ca Species at the Surface of Amorphous Silica As Model Sites. J. Phys. Chem. C. 2008;112:16879-92.

80. Tilocca A, Cormack AN. Exploring the Surface of Bioactive Glasses: Water Adsorption and Reactivity. J. Phys. Chem. C. 2008;112:11936-45.

81. Tilocca A, Cormack AN. Modeling the Water-Bioglass Interface by Ab Initio Molecular Dynamics Simulations. ACS Appl. Mater. Interfaces. 2009;1:1324-33.

82. Pedone A, Malavasi G, Menziani MC, Segre U, Musso F, Corno M, et al. FFSiOH: a new force field for silica polymorphs and their hydroxylated surfaces based on periodic B3LYP calculations. Chem. Mater. 2008;20:2522-31.

83. Tilocca A. Molecular dynamics simulations of a bioactive glass nanoparticle. J. Mater. Chem. 2011;21:12660-7.

84. Neel EAA, Pickup DM, Valappil SP, Newport RJ, Knowles JC. Bioactive functional materials: a perspective on phosphate-based glasses. J. Mater. Chem. 2009;19:690-701. 
85. Knowles JC. Phosphate based glasses for biomedical applications. J. Mater. Chem. 2003;13:2395-401.

86. Ahmed I, Collins CA, Lewis MP, Olsen I, Knowles JC. Processing, characterisation and biocompatibility of iron-phosphate glass fibres for tissue engineering. Biomaterials. 2004;25:3223-32.

87. Neel EAA, Ahmed I, Pratten J, Nazhat SN, Knowles JC. Characterisation of antibacterial copper releasing degradable phosphate glass fibres. Biomaterials. 2005;26:2247-54.

88. Ahmed I, Lewis M, Olsen I, Knowles JC. Phosphate glasses for tissue engineering: Part 1. Processing and characterisation of a ternary-based $\mathrm{P} 2 \mathrm{O} 5-\mathrm{CaO}$ Na2O glass system. Biomaterials. 2004;25:491-9.

89. Uo M, Mizuno M, Kuboki Y, Makishima A, Watari F. Properties and cytotoxicity of water soluble $\mathrm{Na} 2 \mathrm{O}-\mathrm{CaO}-\mathrm{P} 2 \mathrm{O} 5$ glasses. Biomaterials. 1998;19:2277-84.

90. Valappil SP, Ready D, Abou Neel EA, Pickup DM, O’Dell LA, Chrzanowski $\mathrm{W}$, et al. Controlled delivery of antimicrobial gallium ions from phosphate-based glasses. Acta Biomater. 2009;5:1198-210.

91. Tang E, Di Tommaso D, de Leeuw NH. An Ab Initio Molecular Dynamics Study of Bioactive Phosphate Glasses. Adv. Eng. Mater. 2010;12:B331-8.

92. Ainsworth RI, Tommaso DD, Christie JK, Leeuw NH de. Polarizable force field development and molecular dynamics study of phosphate-based glasses. J. Chem. Phys. 2012;137:234502.

93. Christie JK, Ainsworth RI, Di Tommaso D, de Leeuw NH. Nanoscale Chains Control the Solubility of Phosphate Glasses for Biomedical Applications. J. Phys. Chem. B. 2013;117:10652-7.

94. Christie JK, Ainsworth RI, de Leeuw NH. Ab initio molecular dynamics simulations of structural changes associated with the incorporation of fluorine in bioactive phosphate glasses. Biomaterials. 2014;35:6164-71.

95. Ainsworth RI, Christie JK, Leeuw NH de. On the structure of biomedical silverdoped phosphate-based glasses from molecular dynamics simulations. Phys. Chem. Chem. Phys. 2014;16:21135-43.

96. Christie JK, Ainsworth RI, de Leeuw NH. Investigating structural features which control the dissolution of bioactive phosphate glasses: Beyond the network connectivity. J. Non-Cryst. Solids [Internet]. [cited 2015 Jul 30]; Available from: http://www.sciencedirect.com/science/article/pii/S0022309315000332 
97. Sheridan R, Doherty PJ, Gilchrist T, Healy D. The effect of antibacterial agents on the behaviour of cultured mammalian fibroblasts. J. Mater. Sci. Mater. Med. 1995;6:853-6.

98. Ahmed I, Ready D, Wilson M, Knowles J c. Antimicrobial effect of silverdoped phosphate-based glasses. J. Biomed. Mater. Res. A. 2006;79A:618-26.

99. Randall CP, Oyama LB, Bostock JM, Chopra I, O’Neill AJ. The silver cation (Ag+): antistaphylococcal activity, mode of action and resistance studies. J. Antimicrob. Chemother. 2013;68:131-8.

100. Valappil SP, Pickup DM, Carroll DL, Hope CK, Pratten J, Newport RJ, et al. Effect of Silver Content on the Structure and Antibacterial Activity of Silver-Doped Phosphate-Based Glasses. Antimicrob. Agents Chemother. 2007;51:4453-61. 